\title{
Cadaveric Donation - A 10 Years Retrospective Study at D. Y. Patil Medical College, Kolhapur
}

\author{
Dr. Vasudha R Nikam ${ }^{1}$, Dr. Ashalata D Patil ${ }^{2}$
}

\begin{abstract}
Background: Dissection of cadavers is an integral part of medical education and the cadavers serve as a crucial resource of medical education and research in anatomical sciences. Thus continuous availability of the cadavers is one of the major concerns of medical colleges, health science institutions and biomedical research organization in order to fulfill objectives of anatomy curriculum of the undergraduate, postgraduate and researchers in the medical sciences. The present study is an attempt towards creating a database of donated human bodies for the medical education. Objectives: a) To promote the public education for the purpose and importance of body donation. b) To increase the awareness of body donation in female population. Materials and Methods: The cadaveric data from the department of Anatomy, DYPatil Medical College, Kolhapur were obtained for the period 1994-2014 (10 Years); for the purpose of study. The data were retrospectively reviewed and the descriptive analysis was done. Results: The cadaveric donation in the study period was about 179, in which the highest donation was of male cadavers than the female cadaveric donation; also the cadaveric donation was high in year 2006 which was due to increase in the awareness of cadaveric donation in the society. Among total donated bodies 50\% were utilized for medical teaching purpose. Conclusion: Human cadaver is the foundation of medical science. Hence to maintain continuous teaching source it is necessary to promote voluntary body donation programmes in the society and to make females aware of the importance of body donation for the medical education.
\end{abstract}

Keywords: Cadavers, Body donation, Anatomy learning, Anatomy Act

\section{Introduction}

Body donation is defined as an informed and free act of giving one's whole body after death for medical education and research ${ }^{(1,2,3)}$.

Body donation is a gracious act; Shankaracharya firmly believed in concept of body donation and said "Iddham Sharirum paropkarum" i.e. the body is for the use of others and death is not the end; it is the beginning ${ }^{(2)}$. Body donation provides the students and medical researchers with unparallel opportunities to study the human body. Neither Computer nor books can totally replace body dissection in learning the anatomy ${ }^{(2,3)}$. The experience and education gained through the use of human cadaver through the dissection is far superior and very different than the learning provided by artificial substitutes and textbooks ${ }^{(3)}$.

In all the health sciences courses, study of anatomy serves as foundation for understanding the medicine and which is achieved only through the dissection of cadaver ${ }^{(4)}$. It has long been generally accepted that cadavers are essential for the training of medical personnel ${ }^{(5)}$. Apart from their being dissected in anatomy classes, cadavers can be used for practicing surgical skills and developing new surgical techniques and therapeutic advancement in medical science $(6,7)$. Attitude developed during dissection may influence interactions with future patients and families. Hence dissection on cadavers is a landmark to recognize emotional issues that students may confront and to guide them towards becoming humane physicians ${ }^{(7)}$.

The knowledge of anatomy is essential for an efficient general practitioner. It is also necessary for competency of supporting and technical staff of patient treatment and care. Thus body donation is the major and preferred source of cadavers worldwide ${ }^{(8,9,10) \text {. }}$
Anatomy, which is the study of the structure of human body, is one of the most basic and most important subjects studied by medical students when they begin their medical career. Teaching and research in anatomy is based on cadaver dissection. Thus a sound knowledge of anatomy is essential from the beginning of medical education and knowledge obtained through dissection of human body is an indispensable part of the education of health care professionals. With the increase in medical institutions in the country, there is ever increasing demand of cadavers for anatomy dissection ${ }^{(11)}$

Body donation is regulated by various acts according to each country and is considered as one of the modern expressions of solidarity. Relevance of body dissection through the proper use of cadavers is of prime importance before learning living anatomy ${ }^{(11)}$.

Medical education in India is regulated strictly by Medical Council of India. For undergraduate students in first year; the medical education consists of Anatomy, Physiology. Biochemistry and Community Medicine. Out of these four; Anatomy occupies a major portion. The teaching hours according to MCI for undergraduate are about 650 hours for Anatomy compared to 480 hours for Physiology and 240 hours for Biochemistry and 60 hours for Community Medicine each ${ }^{(12)}$.

\section{Role of Anatomy Department in Our Institute}

In our institute 2 hours of each day are exclusively kept for dissection. Dissection is scheduled for five to six days a week over a period of 11 months. Our institute has annual intake of 150 students (100 students till 2005) in undergraduate course MBBS and 4 students per year in postgraduate (MD/MS) requires a steady supply of cadavers to facilitate teaching in Anatomy as per MCI norms. This purpose is fulfilled by body donation programme actively 


\section{International Journal of Science and Research (IJSR) \\ ISSN (Online): 2319-7064}

Index Copernicus Value (2013): 6.14 | Impact Factor (2015): 6.391

done by department of Anatomy in D.Y.Patil Medical College.

In our institute body donation programme was started in 1994. Since then till today due to social awareness; departmental and institutional co-operation, continuous supply of cadavers is always maintained. Hence it has added academically to organize live workshops along with the clinical departments. Also the cadavers are used for museum; as various viscera are displayed as museum specimen as well as in medical education fairs for enlightening the common persons.

The donated cadavers who wished to donate their body after death for medical education purpose when alive and without any objection from the near relatives were accepted. These persons should have natural death and should be free to from contagious disease.

In our institute we started the body donation programme; when the society was unaware about this. Now due to the strong efforts put by the departmental teaching and nonteaching staff the programme is running successfully; with 16 bodies used for the purpose of dissection for first MBBS batch; and 34 bodies in stock.
The present study is an attempt to assess the trends in cadaveric donation, adequacy and profile of the cadavers which were donated to this institution for the purpose of medical education.

\section{Materials and Methods}

The data from the department of Anatomy; DYPatil Medical College, under DYPatil University, Kolhapur were obtained for the period 1994 to 2014; the authors selected a time span of 10 years from 2005 to 2014 for the purpose of the study. The data were retrospectively reviewed and descriptive analysis was done.

The details of cadaver donation (name, age, sex, residence, purpose of donation and fate) are recorded meticulously in a body donation register kept for the purpose in the Department of Anatomy. The following were recorded in tabular form.

a) Total number of cadavers donated each year.

b) Age and sex of donated cadavers.

c) Usage of cadavers.

\section{Observations and Results}

Findings of the study are shown in Table No-1.

Table 1

\begin{tabular}{|c|c|c|c|c|c|c|c|c|}
\hline Sr. No & Year & $\begin{array}{c}\text { Total No of } \\
\text { Cadavers }\end{array}$ & $\begin{array}{c}\text { No of Male } \\
\text { Cadavers }\end{array}$ & $\begin{array}{c}\text { No of } \\
\text { Female } \\
\text { Cadavers }\end{array}$ & $\begin{array}{c}\text { Lowest Age of } \\
\text { Cadavers } \\
\text { years }\end{array}$ & $\begin{array}{c}\text { Highest Age } \\
\text { of Cadavers } \\
\text { years }\end{array}$ & $\begin{array}{c}\text { Average Age } \\
\text { of Cadavers } \\
\text { years }\end{array}$ & Fate \\
\hline $\mathbf{1}$ & 2005 & 10 & 04 & 06 & 60 & 100 & 80 & D-5, DC-1, S-4 \\
\hline $\mathbf{2}$ & 2006 & 28 & 19 & 09 & 47 & 93 & 70 & D-8, M-2, MU-1, S-17 \\
\hline $\mathbf{3}$ & 2007 & 11 & 04 & 07 & 50 & 89 & 69.5 & D-8,P-1, MU-1, S-1 \\
\hline $\mathbf{4}$ & 2008 & 13 & 08 & 05 & 72 & 86 & 79 & D-8, P-1, S-4 \\
\hline $\mathbf{5}$ & 2009 & 08 & 06 & 02 & 58 & 80 & 69 & $\mathrm{D}-6, \mathrm{P}-1, \mathrm{M}-1, \mathrm{~S}-0$ \\
\hline $\mathbf{6}$ & 2010 & 22 & 14 & 08 & 55 & 91 & 73 & $\mathrm{D}-10, \mathrm{P}-1 \mathrm{M}-1, \mathrm{~W}-10, \mathrm{~S}-0$ \\
\hline $\mathbf{7}$ & 2011 & 20 & 12 & 08 & 53 & 90 & 71.5 & $\mathrm{D}-9, \mathrm{P}-1, \mathrm{~W}-10, \mathrm{~S}-0$ \\
\hline $\mathbf{8}$ & 2012 & 24 & 16 & 08 & 59 & 90 & 74.5 & $\mathrm{D}-12, \mathrm{P}-1, \mathrm{~W}-10, \mathrm{~S}-1$ \\
\hline $\mathbf{9}$ & 2013 & 24 & 16 & 08 & 50 & 91 & 70.5 & $\mathrm{D}-12, \mathrm{P}-1, \mathrm{~W}-10, \mathrm{~S}-1$ \\
\hline $\mathbf{1 0}$ & 2014 & 19 & 12 & 07 & 56 & 92 & 74 & $\mathrm{D}-12, \mathrm{P}-1, \mathrm{~S}-6$ \\
\hline TOTAL & & 179 & 111 & 68 & & & & $\mathrm{D}-90, \mathrm{DC}-1$, \\
& & & & & 0 & & & M-4, MU-2,W-40, P-8 \\
\hline
\end{tabular}

(D-Dissection, DC-Decomposed, M-Museum, MUMummification, W-Workshop,

P-PG training, S-Storage)

a) Total number of Cadavers donated during the period of study was- 179

b) Highest number of Cadavers were donated in 2006- 28

c) Lowest number of Cadavers were donated in 2009- 08

d) Total Male Cadavers donated-

e) Total Female Cadavers donated-

f) Youngest age at donation-

g) Eldest age at donation-

h) Average age of donation-

i) Number of bodies in age group between 61-90 years-

j) Number of bodies dissected-

k) Number of bodies decomposed-

1) Number of bodies used for museum-

m) Number of bodies used for mummification-

n) Number of bodies used for PG training-

o) Number of bodies used for workshop-

p) Total number of bodies remained in storage-
Findings of the study are shown in the Table no-1 and Fig No-2. The observations are as follows- 


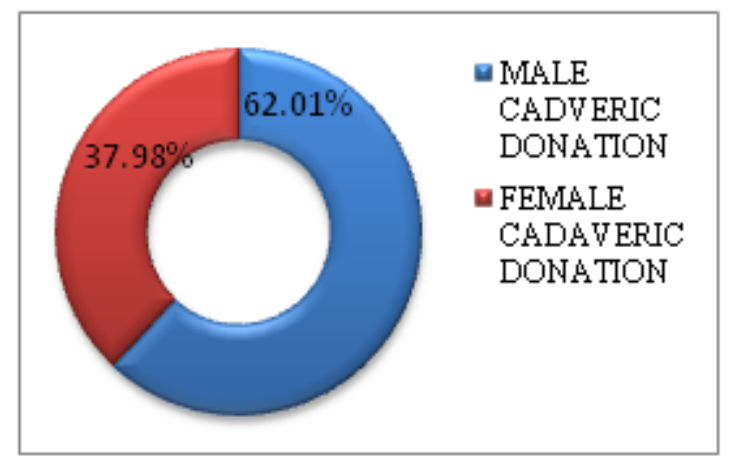

Figure 1: The male and female cadaveric donation-

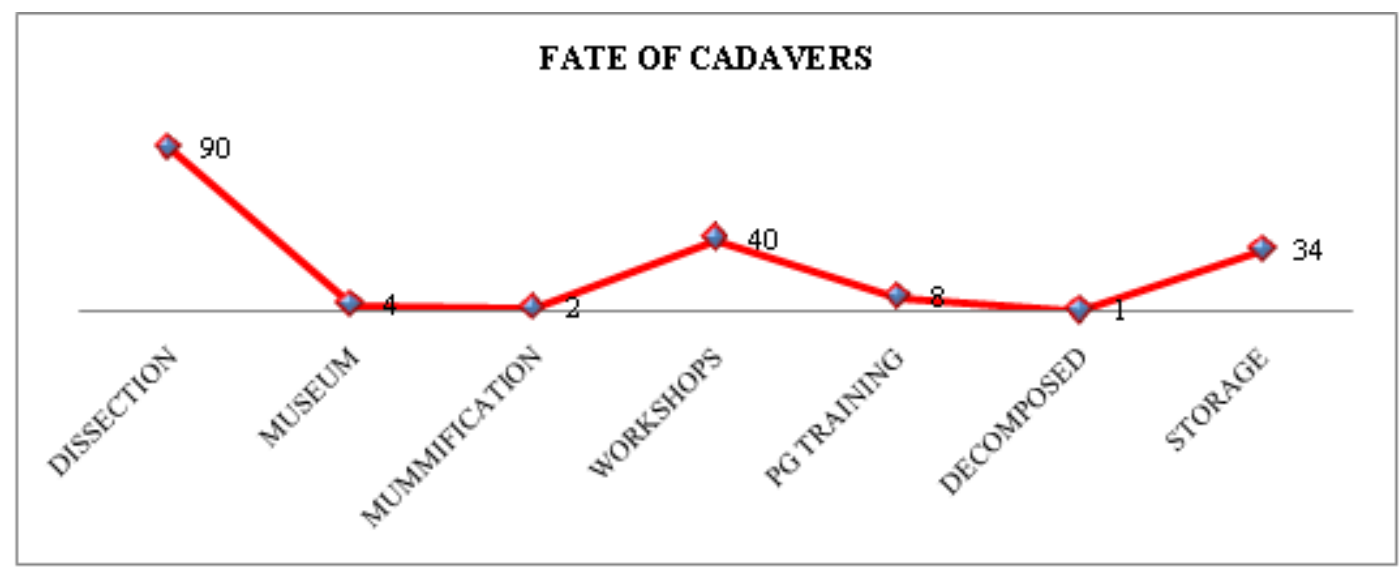

Figure 2: The fate of cadavers-

\section{Discussion}

In the medical profession cadavers and the donated bodies are the principal tools for teaching the anatomy and its other aspects. Hence the need of cadavers is increased in the medical colleges across the country.

Human body is very complex but it conforms to a general pattern. What is described as normal anatomy in textbooks is found less than half the time. This does not mean that rest is "abnormal". They are variants which are present in many individuals ${ }^{(13)}$.

In many medical colleges across the India, there is shortage of cadavers for the purpose of medical education. However due to the Body Donation campaigns and the programmes actively done by our department; we now are having ample of bodies with about 34 in stock.

Some of the investigators found that older age was negatively associated with willingness to the body donation $(12,16,17,18)$. Thus when compared with the other studies the average age for donation in present study was 79.18 years; which was on higher side when compared with the other studies in i.e.; Dr Anirban Sadhu etal; in West Bengal, India which was 68.57 years. This indicates that the healthy lifestyle in Maharashtra as compared to West Bengal.

Some investigators observed that donors were predominantly Males ${ }^{(10,16,17,18)}$ this was also similar to our study (Fig no-1). This indicates that there is less or no awareness among the female group about the body donation across the country. Thus the need of body donation and its importance is very positively seen in the male group.

The increase in number of body donation from 2006 may be due to increase in awareness about the body donation in the society as well as the body donation programmes and campaigns held by our department equally count a lot.

\section{Conclusion}

Human cadavers and human material is the foundation of medical sciences. Hence to provide a sustainable solution to the requirements of health professionals it is desirable to develop and efficiently promote voluntary body donation programmes. The present study is an attempt towards creating a database of donated human bodies for the medical education.

We recommend -

a) To promote the public education for the purpose and importance of body donation.

b) To increase the awareness of body donation in female population.

c) To make aware the students admitted in first MBBS; with them we can increase the awareness among their families, relatives and friends.

d) To promote new technique of soft embalming in cadavers so more cadaveric workshops can be organized along with skill training for the health professionals and residents can be achieved.

At last appreciation to the donor and its family for their valuable contribution to the society should not be forgotten. 


\section{International Journal of Science and Research (IJSR) \\ ISSN (Online): 2319-7064}

Index Copernicus Value (2013): 6.14 | Impact Factor (2015): 6.391

\section{Acknowledgement}

Thanks to President, Chancellor, Vice Chancellor, Dean of the Medical College, and my colleagues, D.Y.Medical College, Dr.D.Y.Patil University, Kolhapur.

\section{References}

[1] S A Rokade, B H Bahetee; Body Donation A Review. Medical Journal of Western India; Feb 2013, Vol 41, Issue 1, pp-36-41.

[2] Dr S Saritha, Dr M Vittoo rao, Dr Sumangala, Dr G Supriya, Dr Praveen Kumar; Voluntary Body DonationThe Gift That Lives On Forever; International Journal of Advancements in Research and Technology; Oct 2012, Vol-1, Issue 5, pp-1-8.

[3] Galani Meha Kishor, Muley S K. Shelke D S; Body Donation Need of Today's Sciences; May 2013; Vol 1, Issue 2, pp-79-84.

[4] Singh A K, Sharma R C, Sharma R K, Musmade D M; Challenges in Cadaver Availability For Learning and Research In Medical Sciences; Oct 2011, Vol 2, Issue 2, pp-67-71.

[5] Sitiporn Agthong, Viroj Wiwanitkit; Cadaveric Donation: A Retrospective Review at The King Chulalongkorn Memorial Hospital, Bangkok; Cadaveric Donation in Thailand, 2002, Vol-33, Issue 3, pp-166167.

[6] Bunprasert T; The New Potential of Surgical Training: Surgical Training Centre, Chula Medical Journal; 1998, 42, pp-413-415.

[7] Bourguet CC, Whittier WL, Taslitz N; Survey of educational roles of Faculty of anatomy departments; Clinical Anatomy, 1997, Vol-10, Issue-4, pp-264-271.

[8] Sehirli US, Saka E, Sarikaya O; Attitudes of Turkish anatomist towards cadaveric donation; Clinical Anatomy, 2004; Vol-17, Issue-8, pp-677-681.

[9] Ballala K, Shetty A, Malpe SB; Knowledge, attitude and practices regarding whole body donation among medical professionals in a hospital in India; Anatomical Science Education, 2011, Vol-4, Issue-3.pp-142-150.

[10] Dr Anirban Sadhu, Dr Rudradevi Meyur, Dr Banani Kundu, Dr Sharmista Biswas, Dr Subhasis Chakraborthy; Trends in body donation for medical education: 10 year retrospective study; Indian Journal of Basic and Applied Medical Researcher; Sep 2103, Vol2, Issue-8, pp-1089-1092.

[11] Rajkumari Ajita, Y Ibochouba Singh; Body Donation and Its Relevance In Anatomy Learning- A Review; Journal of Anatomical Sciety of India, 20007,Vol- 56, Issue-1, pp- 01-06.

[12] Medical Council of India. Medical Council of India regulations on Graduate medical Education 1997.

[13] Moore KL, Dalley AF; Introduction to clinically oriented Anatomy. In Moore KL and Dalley AF eds. Clincally Oriented Anatomy, Philadelphia: Lipponcott Williams and Wilkins, 2006; 12.

[14] Boulware LE, Ratner LE, Sosa JA, Cooper LA, Laveist TA, Powe NR; Transplantation; 2002, Vol-73, Issue-10, pp-1683-91.

[15] Armstrong GT, Age: An Indicator of willingness to donate. Journal of Transplant Coord; 1996, Vol-6, Issue-4, pp-171-173.
[16] Alashek w, Ehtuish E, Elhabashi A, Emberish W, Mishra A; Reasons for willingness of Libyans to donate organs after death; Libyan Journal of Medicine, 2009, Vol-4, Issue-3, pp-111-113.

[17] Boulware LE, Ratner LE, Cooper LA, Laveist TA, Powe NR; Whole body donation for medical science: A Population Based Study. Clinical Anatomy 2004, Vol17, Issue-7, 570-577.

[18] Dulzen DE, Brammer CM, Bernerd JC, Keyser MR; Survey of cadaveric donors to a body donor program: 1978-1993, Clinical Anatomy, 1996, Vol-9, Issue-3, $183-192$

\section{Author Profile}

Dr. Mrs. Vasudha Nikam is Professor and Head, Department of Anatomy, D.Y.Patil Medical College, DYPatil University, Kasaba Bawada, Kolhapur-416006, Maharashtra

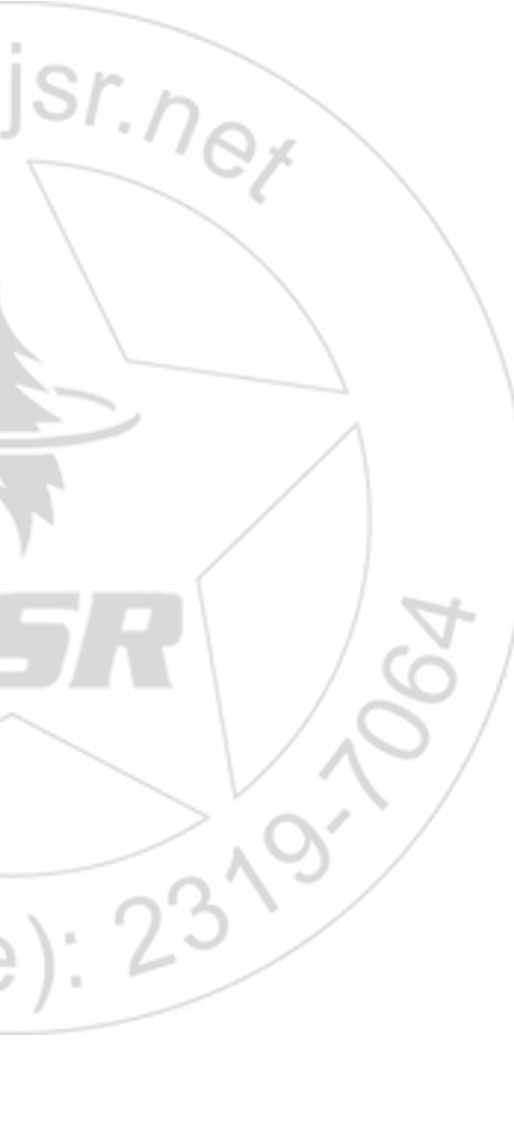

